\title{
Segmenting Preferences and Habits of Transit Users and Non-Users
}

\author{
Kevin J. Krizek, University of Colorado, Boulder/Denver, CO
} Ahmed El-Geneidy, University of Minnesota, Minneapolis, MN

\section{Abstract}

Ridership is a key goal in the transit industry. Conventional transit analysis focuses on two types of users - captive and choice riders-but rarely aims to understand the preferences of non-transit riders. This research aims to better understand habits and preferences - for both users and non-users of the transit system - as they relate to the transit market in the Twin Cities metropolitan area. Our research first articulates different broad market segments commonly considered in transit research and follows by describing how specific features of transit service characteristics may play out in influencing demand. We describe the source of two surveys analyzed in this application, one for existing transit users and a separate one for non-users. Our analysis approach employs factor and cluster analysis to shed light on preference and other characteristics for eight different segments of transit users or potential transit users. The discussion section and conclusions highlight the findings and prescribe relevant policy recommendations.

\section{Introduction}

In 2000, Metro Transit, the largest local transit provider for the Twin Cities metropolitan area, served more than $73,000,000$ unlinked passenger trips. Three years later, this number dwindled to $67,000,000$ unlinked passenger trips, representing 
a decline in demand for public transit use unique among major transit agencies across the country. From the perspective of the Metro Transit, matters turned upward in 2005 with the opening of the Hiawatha Light Rail. Overall, transit ridership increased 30 percent relative to 2004 (due in large part to the light rail). The question remains, however, whether such fluctuations were merely a reflection of new service or if there were markets of potential transit users who previously had unmet needs?

Like many metropolitan areas, Metro Transit faces the challenge of serving a diverse population in the Twin Cities, including those with widely varying habits and preferences for transit services. This analysis aims to better understand such habits and preferences-for both users and non-users of the transit system-as they relate to the transit market in the Twin Cities metropolitan area. Our research first articulates different broad market segments commonly considered in transit research and follows by describing how specific features of transit service characteristics may play out in influencing demand. We describe the source of two surveys analyzed in this application, one for existing transit users and a separate one for non-users. Our analysis approach employs factor and cluster analysis to shed light on preference and other characteristics for eight different segments of transit users or potential transit users. The discussion section and conclusions highlight the findings and prescribe relevant policy recommendations.

\section{Defining Populations}

\section{Captive and Choice Users}

Transit research and analysis commonly delineates two types of users: captive and choice riders. The American Public Transportation Authority defines captive riders as those "who do not have a private vehicle available or cannot drive (for any reason) and who must use transit to make a desired trip" (American Public Transportation Association 2003). Captive users rely mainly on transit as their main mode of transportation (at least for certain destinations, e.g., work); choice users (also referred to as discretionary riders) have alternative modes to use to reach varied destinations, yet for certain purposes, they prefer to use transit (Jin, Beimborn and Greenwald 2005). For some transit systems in the United States that provide a variety of reliable services, choice riders outweigh captive riders in terms of magnitude. The Chicago Transit Authority (CTA) reports that more than two-thirds of its riders were choice (Chicago Transit Authority 2001); the Tri- 
County Metropolitan District of Oregon (TriMet) in Portland claims their choice users amount to three-quarters of their ridership.

The differences between the two populations are often distinct, particularly from a socio-demographic perspective. The literature often associates transit captive riders with characteristics such as being low income, elderly or children, having disabilities, families whose travel needs cannot be met through car use, and those who chose not to own or use personal transportation (Polzin, Chu and Rey 2000). Choice riders demonstrate greater variability in their composition. A key outcome in such deliberations, however, is that losses in transit ridership are often attributed to choice riders. This assumption is based on the notion that choice riders are more sensitive to issues such as fare and service quality than captive riders (Jin, Beimborn and Greenwald 2005). Choice riders are more sensitive to potentially negative transit changes because they have alternative mobility options available to them. Furthermore, changes in the captive riders are mainly related to a change in their captivity status-for example, acquiring a vehicle or change in income so they can afford the cost of making a trip with another mode.

\section{Potential Users and Auto Captives}

The above descriptions, choice and captive, apply only to users of the transit system; they say nothing about non-users. For example, a survey conducted after the opening of the Orange Line in Chicago, part of the CTA rail service, revealed that 25 percent of the users of this line were new to transit. Analysis of survey data determined this population was largely represented by former automobile commuters and/or those who took new trips for which the automobile was available (LaBelle and Stuart 1996). In some environments, this suggests there may be a latent demand for new transit users-a common unknown in the transit industry.

Unfortunately, there remains little research uncovering characteristics of the non-transit using population. Some transit systems have administered surveys to non-user populations. Other published efforts that aim to glean information about non-users tend to be extremely specific to specific transit services (e.g., the Carolinian passenger train) or are too broad in their application to understanding the influence of specific transit characteristics (e.g., the PRIZM application dividing households into 62 basic neighborhood types based on social rank, household composition, mobility, ethnicity, urbanization, and housing) (Elmore-Yalch 1998). 
The transit literature needs a strategy to parsimoniously understand the variety of preference characteristics among non-users. Similar to the above classification of captive versus choice riders, non transit users may be considered as two distinct populations: potential riders and auto captives. Potential riders would include those not currently using transit for a variety of reasons and/or concerns but may consider the idea of using transit, given specific conditions (e.g., a known trip from home to the doctor's office). New transit users would be derived from the potential rider population. Auto captives, on the other hand, are exclusively auto users who either would not realistically consider using transit or fail to have transit as an available mode. Given the automobile dominated society in most of the U.S., this leaves most transit agencies trying to attract use from the former population: potential riders. In particular, it is important to uncover the factors that help motivate a potential rider to become a choice rider.

\section{Commuter Frequency}

An additional issue important to consider relates to the regularity in which users may employ transit services. For example, Siddall, Pitstick and Allen (2006) used the frequency of using transit service to better understand the transit market in Chicago. Regular commuters include workers and/or students that regularly travel to the same destination on regular basis. Such users are generally more aware of the mean and variance in travel time. A second population would include irregular commuters (or other travelers) with less frequent or more irregular travel patterns. Similarly, non-riders can be divided into the similarly-natured groups as regular and irregular commuters.

\section{Factors Affecting the Demand for Transit}

Several factors influence anyone's decision to use transit versus other modes-a topic well covered in the literature. Here, we briefly review some of the prominent factors influencing transit ridership. Traditionally, researchers refer to the myriad costs of using transit-costs related to fares, time, inconveniences, etc. The Transit Capacity and Quality of Service Manual (TCQSM) (Kittelson \& Associates 2003) provides a comprehensive approach for understanding the transit trip decision making processes. We more fully describe some of the predominant factors/costs, particularly as they relate to the survey data we analyze in this application. 
- Service frequency: Factors related to the spatial and temporal availability of service at both ends of the trip (Kittelson \& Associates 2003) and, of course, the presence or absence of transit service near origin and destinations are major factors in any decision (Murray 2001). Passengers value their waiting time the most, at a level two to three times that of in-vehicle-time (Mohring, Schroeter and Wiboonchutikula 1987). It is also reported that ridership is expected to increase by 0.5 percent in response to each 1 percent of service increase (Evans 2004). Accordingly, any changes in the above-mentioned factors are expected either to increase or decrease the demand for transit.

- Access and egress: Much research also relates ridership to access; the more accessible the bus stops, the higher the use (Hsiao et al. 1997; Polzin, Pendyala and Navari 2002). This might not always be the case, however, since ridership depends on additional variables such as service variability and /or socio-demographic information. The variability and frequency of service represent two basic factors that affect demand at a stop. Several studies suggest contradictory outputs regarding the elasticity of demand for transit. Some research indicates that decreases in run time of a route increases passenger demand more than other variables (Rodriguez and Ardila 2002; Lago, Mayworm and McEnroe 1981). However, such conclusions are mostly based on captive riders. Other studies indicate, as mentioned above, that passengers are more sensitive to out-of-vehicle time (Kemp 1973; Pushkarev and Zupan 1977; Lago and Mayworm 1981; Mohring, Schroeter and Wiboonchutikula 1987). Two comprehensive studies regarding the elasticity of demand with respect to fare found that demand for transit service is relatively inelastic when it comes to changes in price (Goodwin 1992; Oum, Waters II and Yong 1992). Meanwhile others found the value associated to time is higher than the fare (Mohring, Schroeter and Wiboonchutikula 1987).

- Time and cost: Domencich, Kraft and Valette (1968) estimate the elasticities of demand for public transit in relation to all aspects of time and cost. They found that passenger demand will decrease by 3.9 percent for a 10 percent increase in travel time, while demand will decrease by 7 percent for each 10 percent increase in access, egress, and waiting time. These findings were reported and validated later by Kraft and Domencich (1972) and O'Sullivan (2000). Although this application combines both wait time and access into one category, the study is notable in its focused attention to this topic. 
- Other users: It is also important to note that transit demand can be related to the number of potential users along a route. Levinson (1985) developed a model to forecast ridership along bus transit routes. He used the following factors: population, employment, travel time, car ownership, walking distance to bus stops, and demand elasticity factors. The virtue of this study is that it provides a reasonable approach to understanding the demand for transit. His model implies the idea that transit riders are captive or not; he, therefore, includes variables such as travel time (to pick up preferences for choice riders) and demographic variables (to pick up characteristics of non-choice riders).

Generalizing the findings from the above summary is difficult; however, predominant themes can be used as indicators for expected changes in passenger demand due to potential improvements in the current transit service. Both captive and choice riders are affected by changes in service. Choice riders tend to be more sensitive since they have an alternative to not use the system given decreases in the level of service. (Jin, Beimborn and Greenwald 2005). Potential riders can be attracted by improvements in the levels of service and decline in both in-vehicle and out of vehicle time. In terms of regularity of commuting, it is important to note that regular transit users are more sensitive to service reliability and its status. Meanwhile irregular commuters tend to be more sensitive to information (maps and schedules) and availability of service.

\section{Data}

Our analysis is based on data collected for Metro Transit in the form of two different surveys, one of current users in 2001 and a separate survey of non-users in 1999. The survey of transit users, totaling 4,408 observations, contained 83 questions covering a variety of topics including the trip origin and destination, rider satisfaction, and concerns about the system, in additional to standard sociodemographics and years as transit users. Detailed issues from the survey included questions related to riders' perception of safety, cleanliness of the service, drivers' attitudes, customer support services, transit service reliability and on-time performance, and a set of socio-demographic indicators.

The non-rider survey was conducted through random digit dial phone interviews across the Twin Cities metropolitan area. The first question was, "Are you currently a Metro Transit user?" A "yes" response terminated the interview; a "no" response prompted the interviewer to proceed with the remaining set of questions. A total 
of 500 phone interviews were conducted in November and December of 1999. Each interview contained 138 questions oriented to non-riders, covering a variety of topics including reasons not using transit, perceptions of safety and comfort of using transit, concerns related to drivers attitude, concerns related to amenities, concerns related to the commute characteristics, concerns of service reliability if using transit is an option, the level of attractiveness of the current service, and various socio-demographic and economic characteristics.

Two filters helped further establish criteria for the data we ultimately analyzed. Because we were primarily interested in perceptions of the different aspects of transit service, we focused on questions from the surveys directly related to these phenomena or relevant socio-demographic information. Second, squarely satisfying criteria for usable data based on our analysis approach (described below) required that the data be interval in nature. The two filters precluded us from using all data from all surveys. Several responses from both surveys were not interval data and therefore not compatible with the analysis methodology; hence, they were not incorporated into the analysis. Nonetheless, combined, the data satisfying our criteria represent extremely rich surveys which, after critical analysis, yield useful information to help better understand the transit markets.

\section{Analysis Approach}

Our analytical approach employed statistical procedures to uncover separate characteristics of the user versus non-user populations. We first used principal component factor analysis to learn how each of our measures (responses to questions) initially relates to one another. Factor analysis extracts a small number of fundamental dimensions (factors) from a larger set of intercorrelated variables measuring various aspects of those dimensions. It is used to study the patterns and relationships among many variables with the goal of discovering something about the nature of the measured variables that affect them. By doing so, we are able to better understand how specific elements within one dimension (e.g., waiting time for the next bus) relate to outcomes in another dimension (e.g., drivers' behavior), thereby capturing possible interdependencies (Maruyama 1998). While factor analysis is widely used in social science research, to our knowledge it has limited use in the transit literature. Of the few studies uncovered, Syed and Khan (2000) identified key factors that serve as determinants of public transit ridership from attitude survey responses in 1995. Another study by Outwater et al. (2003) used 
a similar technique to uncover the characteristics of ferry riders in San Francisco area.

Using the factor analysis as the basis for the "reduced-form" data, the second step in our analysis employs k-means cluster analysis. Cluster analysis is a data analysis tool to sort different objects (in this case, a reduced form version of the responses to the survey questions) into groups in a way that the degree of association between two objects is maximal if they belong to the same group and minimal otherwise. The aim is to determine how each of the factors combine to represent different taxonomies of groups of both transit users as well as for non-users. In general, when one needs to classify a mountain of information into manageable, meaningful groups-our aim in analyzing both of these transit-related surveysfactor analysis and cluster analysis proves to be a valuable strategy. The below text is divided into two parts; the first focuses on results from the user survey, the second on the non-user survey.

\section{User Characteristics}

We used responses from 33 questions to in the factor analysis for the users. The analysis revealed eight factors with eigenvalues greater than 1 and, after inspection, we decided to retain all eight values. The results of the factor loadings are displayed in Table 1 and the variables are listed in order of the size of their factor loadings (i.e., coefficients). Within each of the eight blocks of variables, the high values (above about 0.5 in absolute value, indicated in bold) are all in a single column. A separate column represents each of the eight blocks (aka factors). Cumulatively, these eight factors explain almost 62 percent of overall variation in the data. After inspecting the contributing variables to each factor loading, we assigned labels to each of the eight factors as indicated below in bold:

1. derived from five measures assessing the driver's attitude,

2. a variety of questions related to customer service,

3. factors related to the specific type of transit service,

4. how users value issues of reliability and confidence in service,

5. variables related to household income and how the user values time,

6. concerns about cleanliness and comfort,

7. concerns about safety, and

8. other personal characteristics. 


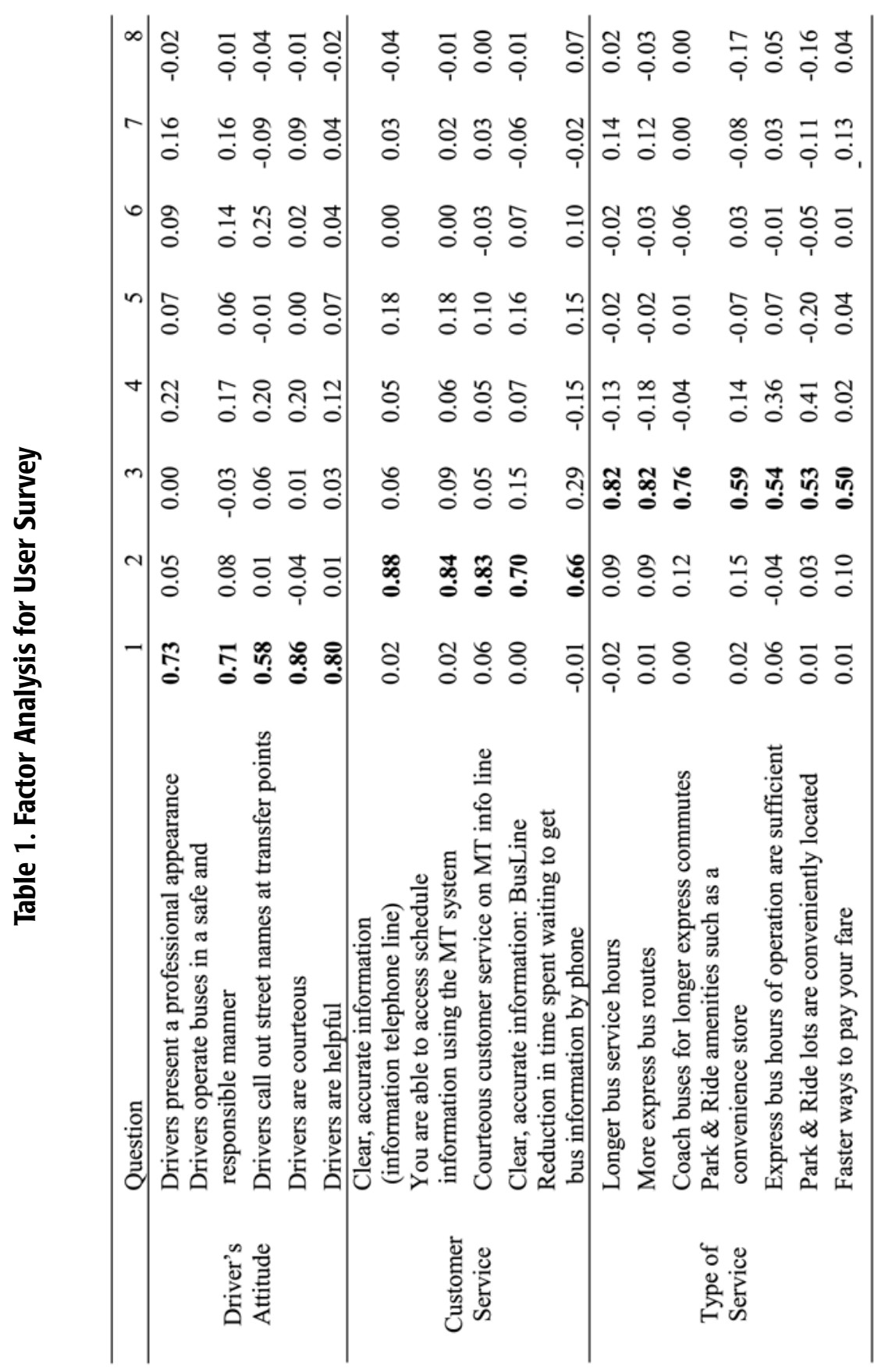




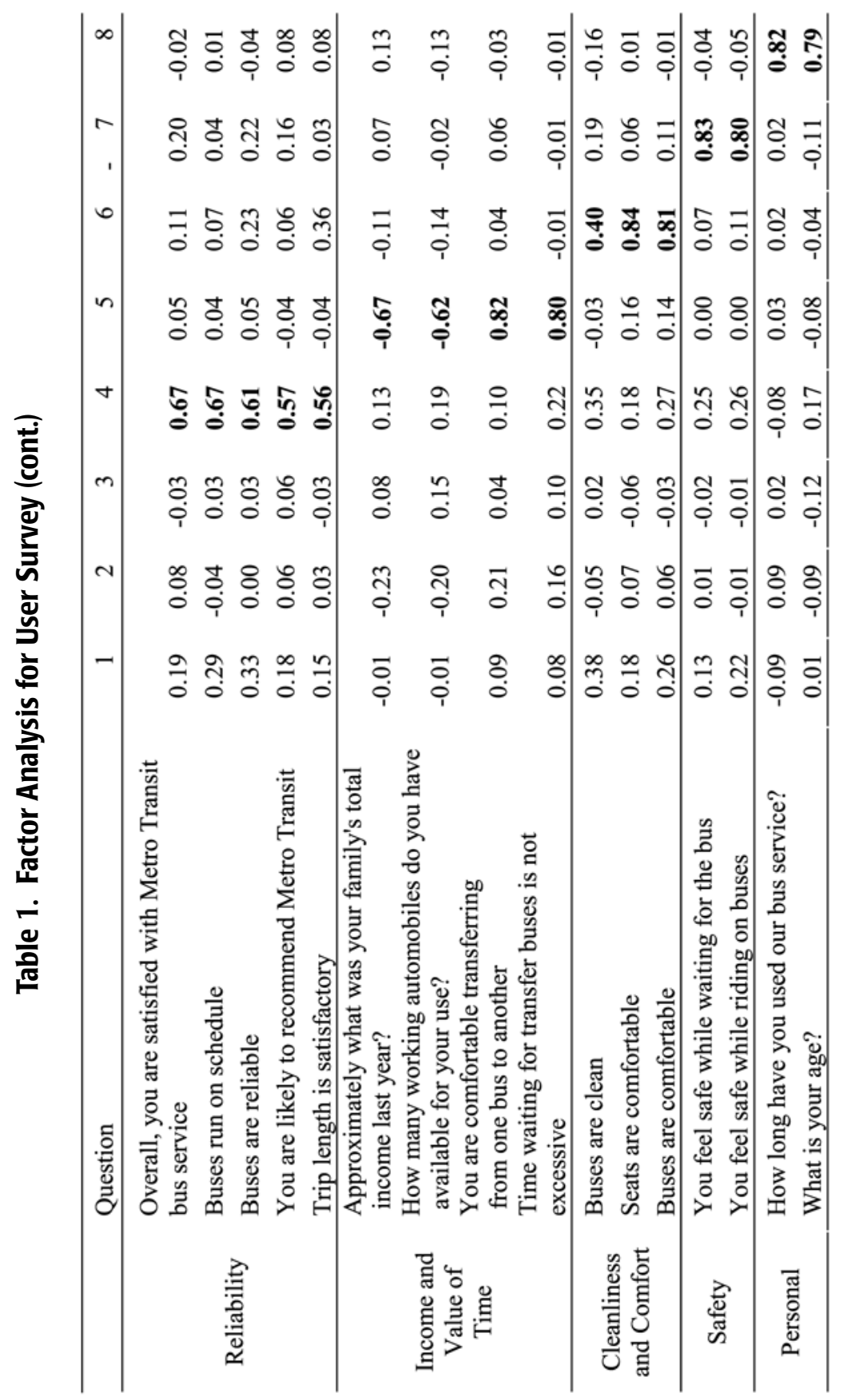


Having identified how each of the responses relate to one other, iterative cluster analysis identifies groupings of riders with similar concerns related to characteristics or preferences of the transit service. The clustering process uses the $\mathrm{K}$-means statistical routine and these groupings are referred to as rider's type (captive and/or choice). An important issue to address up front is the most appropriate number of clusters to accommodate the full range of known types of riders. A combination of four factors ultimately guided our decision: (a) statistical output, (b) the manner in which the output is transferable for transit policy, (c) lessons from past research efforts, and (d) common sense and intuition. Since the prevailing literature suggests two types of riders, choice and captive, we started with two clusters.

The output using two clusters was dominated by the personal factor, which had the lowest loading in the factor analysis. Accordingly, we sought greater variation in our ability to surmise about more than two groups. The values for a four-cluster solution are presented numerically in Table 2. Examining the defining characteristics and preferences of each cluster reveals four distinct populations that are also consistent with predominant themes from the literature that was generally discussed earlier in the manuscript related to market segmentation (Jin, Beimborn and Greenwald 2005; Siddall, Pitstick and Allen 2006). The groups not only split between choice and captive users, but also account for preferences that often distinguish between regular and irregular commuting habits.

\section{Table 2. Values of Cluster Centers}

\begin{tabular}{lcccc}
\hline & \multicolumn{2}{c}{ Choice Riders } & \multicolumn{2}{c}{ Captive Riders } \\
& Regular & Irregular & Irregular & Regular \\
\hline Driver's Attitude & -0.14 & 0.22 & 0.17 & -0.13 \\
Customer Service & 0.44 & -0.38 & 0.01 & -0.21 \\
Type of Service & 0.35 & -0.60 & 0.24 & -0.09 \\
Reliability & 0.18 & -0.10 & -0.31 & 0.09 \\
Income and Value of Time & 0.73 & 0.48 & -0.15 & -1.15 \\
Comfort & 0.34 & 0.25 & -1.50 & 0.44 \\
Safety & 0.21 & -0.56 & 0.10 & 0.15 \\
Personal & 0.39 & -0.77 & -0.01 & 0.18 \\
\hline
\end{tabular}


The height and direction of each bar in Figure 1 graphically presents the value of the cluster center for each of the previously defined eight factors. A first observation of our analysis is that captive riders comprise 46 percent, while choice riders represent 54 percent, of the surveyed population. On a more detailed level, several defining characteristics stand out. Regular choice riders ( 32 percent of the sample) are affected by all the factors except for driver's attitude. Within the transit industry, it is known that drivers change routes every three to four months and are given the choice to change the time of their operation and the route they serve. For a regular user, we would, therefore, expect the impact of the driver's attitude to have minimal importance compared to other factors. Reliability, income and value of time, customer service, and type of service have the greatest effect on regular choice riders. Irregular choice riders (22 percent) are those who tend to choose transit as an alternative to other modes. They care about the driver's attitude, are searching more for comfort in the trip, and value their time more than captive riders. In addition, the high negative ranking on the personal factor suggests they are more irregular transit users.

Figure 1 also shows the division of captive riders into regular and irregular commuters. Captive irregular riders tend to use transit occasionally and do not have other alternatives. The factors affecting them are the driver's attitude, type of

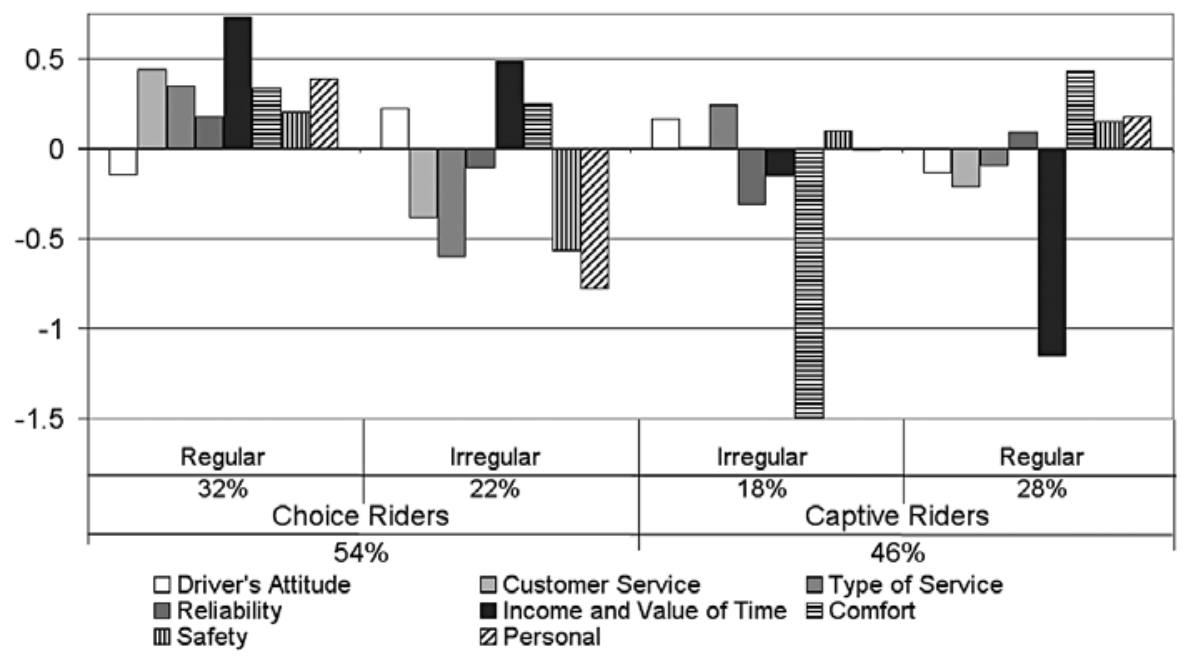

Figure 1. Cluster Analysis for Riders 
service, customer support, and safety. Finally, the fourth type of riders are coined regular captive. Regular captive riders are those who do not have any other option but transit. Since they are regular users, they do care about reliability of the service, bus comfort, and safety. The personal factor indicates they are regular users of the service.

\section{Non-User Characteristics}

Our analysis of non-users relied on a similar approach to that described above, but for a distinctly different set of variables. We analyzed a total of 36 questions from the non-rider survey, and the factor analysis suggests 11 different factors, all with eigenvalues greater than 1. Table 3 lists the variables in order of the size of their factor loadings (i.e., coefficients), shown for each of 11 different blocks of variables (aka factors), representing:

(1) matters related to safety and comfort,

(2) issues surrounding the driver's attitude,

(3) various levels of service amenities and special requests,

(4) characteristics of their typical commute,

(5) how important matters of reliability might be,

(6) attributes of the location and type of transit service,

(7) service attractiveness,

(8) how matters of travel cost factor into their commute,

(9) the presence of children to care for,

(10) travel time, and

(11) personal characteristics.

High values (above about 0.5 in absolute value, indicated in bold in the table) are all in a single column. Cumulatively, the 11 factors extracted explain almost 71 percent of overall variation in the data.

Relying on iterative cluster analysis, we uncovered four distinct clusters among the non-user population. Again, we thought it was prudent to separate the population for auto captives among four groups: those who have an irregular commute pattern, those with regular commute patterns, potential riders with regular commute patterns, and potential riders with irregular commute patterns. The values 


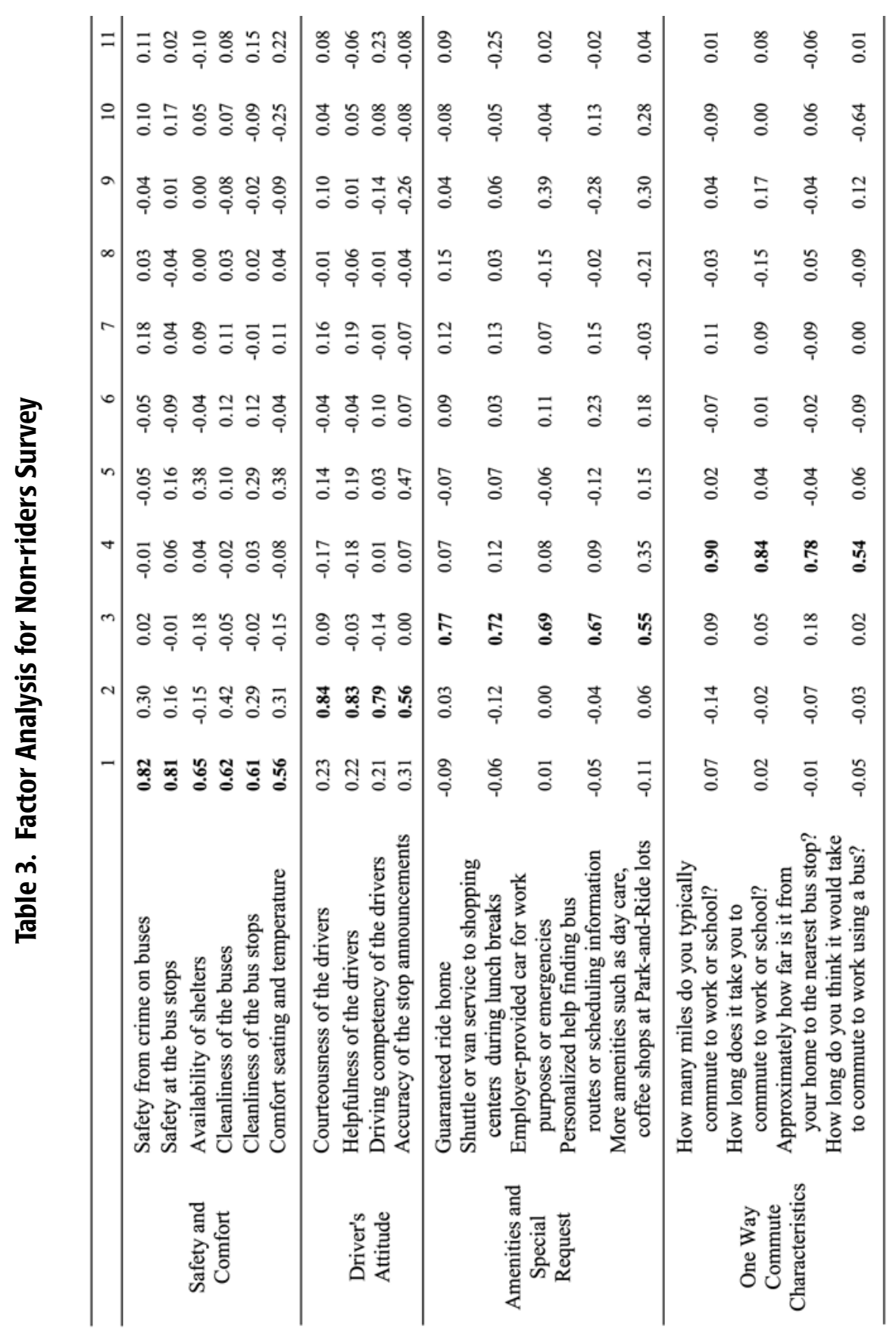




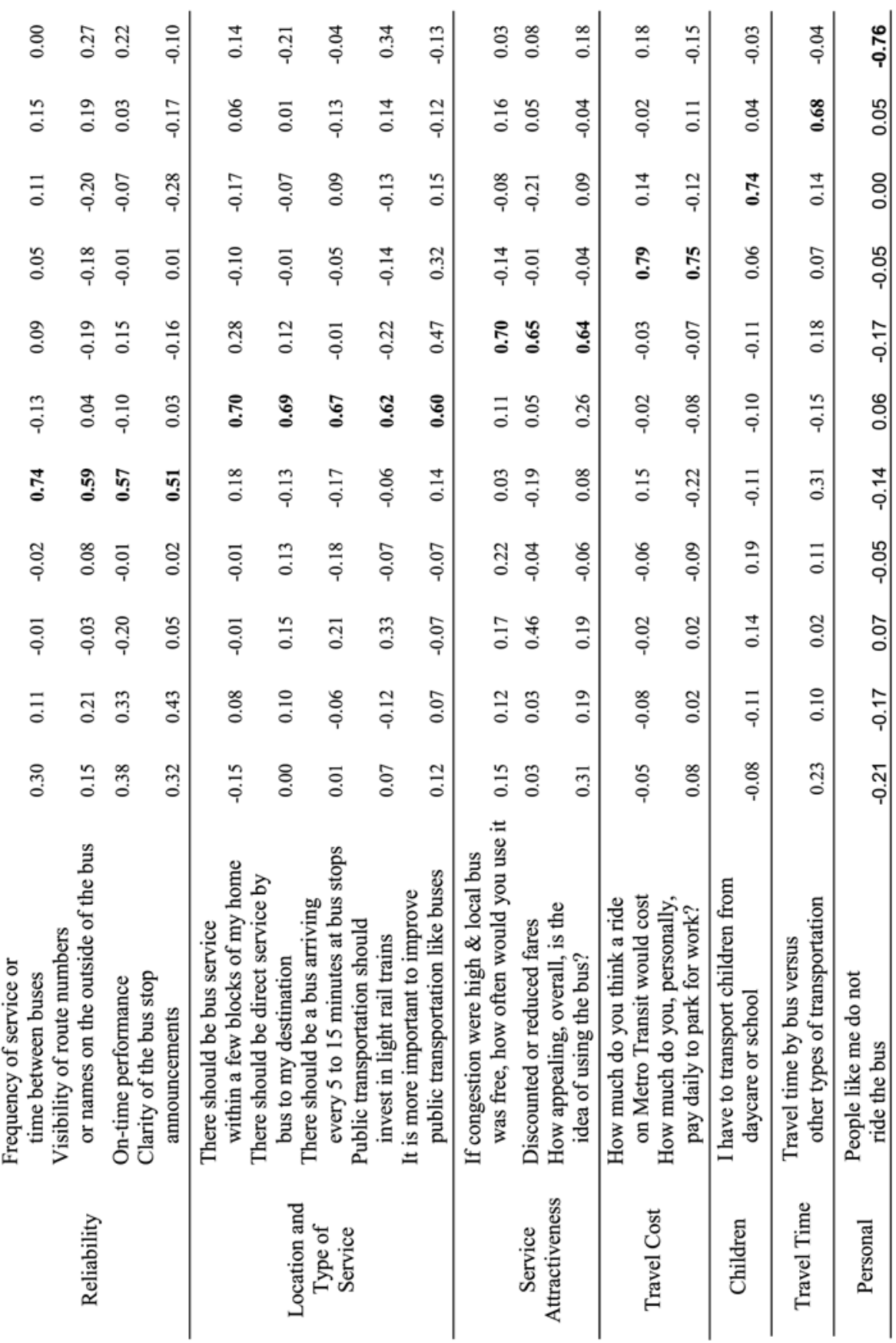


of the cluster centers for each type of non-rider are presented numerically in Table 4 and graphically in Figure 2. Auto captives represent 47 percent, while potential riders represent 53 percent of the surveyed population.

Table 4. Cluster Centers for Non-users

\begin{tabular}{lcccc}
\hline & \multicolumn{2}{c}{ Auto Captives } & \multicolumn{2}{c}{ Potential Riders } \\
& Irregular & Regular & Irregular & Regular \\
\hline Safety and Comfort & -0.38 & -0.31 & -0.07 & 0.59 \\
Driver's Attitude & -0.47 & -0.03 & 0.25 & -0.13 \\
Amenities and Special Request & -0.12 & -0.20 & -0.25 & 0.55 \\
Commute Characteristics & -0.82 & 0.15 & -0.39 & 0.13 \\
Reliability & 1.20 & -0.02 & -0.20 & 0.14 \\
Location and Type of Service & -0.07 & 0.16 & -0.02 & -0.23 \\
Service Attractiveness & -0.21 & -0.41 & 0.31 & 0.41 \\
Travel Cost & 6.29 & -0.18 & 0.13 & -0.16 \\
Children & 1.14 & 0.10 & -0.57 & 0.27 \\
Travel Time & -0.07 & 0.07 & 0.57 & -0.60 \\
Personal & 1.45 & 0.50 & -0.84 & -0.16 \\
\hline
\end{tabular}

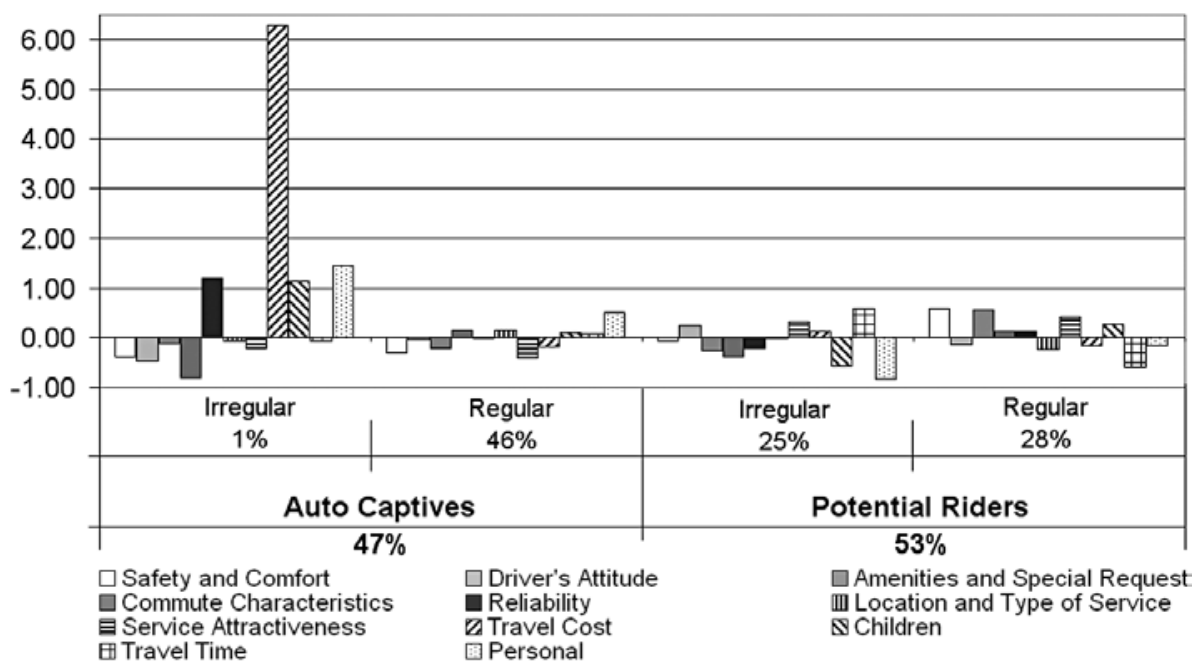

Figure 2. Non-rider Cluster Analysis 
Auto captives are the type of commuters unwilling to change their travel mode to use transit. For example, both regular and irregular commuters who are auto captives answered positively for the questions stating "People like me do not ride transit" and negatively to "How appealing, overall, is the idea of using the bus?" The primary concerns for irregular auto captives are driving children to school and/or daycare, reliability of service, and travel cost (cost of traveling with transit and amount paid for parking fees at their destinations). Irregular auto captive commuters represent only 1 percent of the surveyed population. Regular commuters, whom we consider auto captives, represent 46 percent of the surveyed population. They tend to have similar concerns as irregular commuters in term of driving children to schools, but their primary concern is the characteristics of the commute (they tend to travel further distances than irregular commuters). Additional issues are the location and type of service provided (how far the stops are from their origins and destinations and the frequency of service), and travel time.

Potential riders are mainly commuters who answered negatively to the question "People like me do not ride transit" and positively to "How appealing, overall, is the idea of using the bus?" Potential riders are commuters willing to change their commuting behavior in case some specifications are present in the current transit service (service attractiveness factor). They can also be classified into two categories, regular and irregular commuters based on the definition of the literature of regular and irregular transit commuters and the factors affecting each group.

Irregular commuters, whom we classify as potential riders, are mainly concerned with the driver's attitude, the cost of the service, and travel time. Regular potential riders gravitate towards safety and comfort of the service and amenities related to the service and some special requests (special requests include the availability of high frequency services during peak and off peak for emergencies and the availability of shuttle vans at work locations to shopping areas). Other concerns include commute characteristics, reliability of service, and dropping children to daycares and schools as part of their commute. Irregular potential riders compose 25 percent of the surveyed population, while regular potential riders compose 28 percent of the same population.

\section{Discussion}

Our analysis demonstrates how, using statistical analysis of different surveys, the market for existing transit services can be divided into eight different types of com- 
muters with varying preferences. The crudest divide is between regular and irregular commuters; however, the analysis yields finer distinctions. Users of the system can be divided into captive and choice riders, while non-users can be divided into auto captives and potential riders. Figure 3 illustrates such segmentation.

There are notable similarities in the habits and preferences between choice riders (from the user analysis) and potential riders (from the non-user analysis). For example, they prize reliability, travel time, type of service, and comfort. These population segments do not represent the die hard users or those who likely would not use transit. They represent a middle ground of potential users that transit agencies are very interested in targeting. We therefore label the area including both choice riders and potential riders as the "area to market transit services"- the segment of the transit market that an agency can either attract riders from or lose riders to. Other types of travelers certainly exist but are not included in this analysis due to the small segment they would represent (e.g., bicyclers and walkers) and the lack of appropriate data to analyze them.

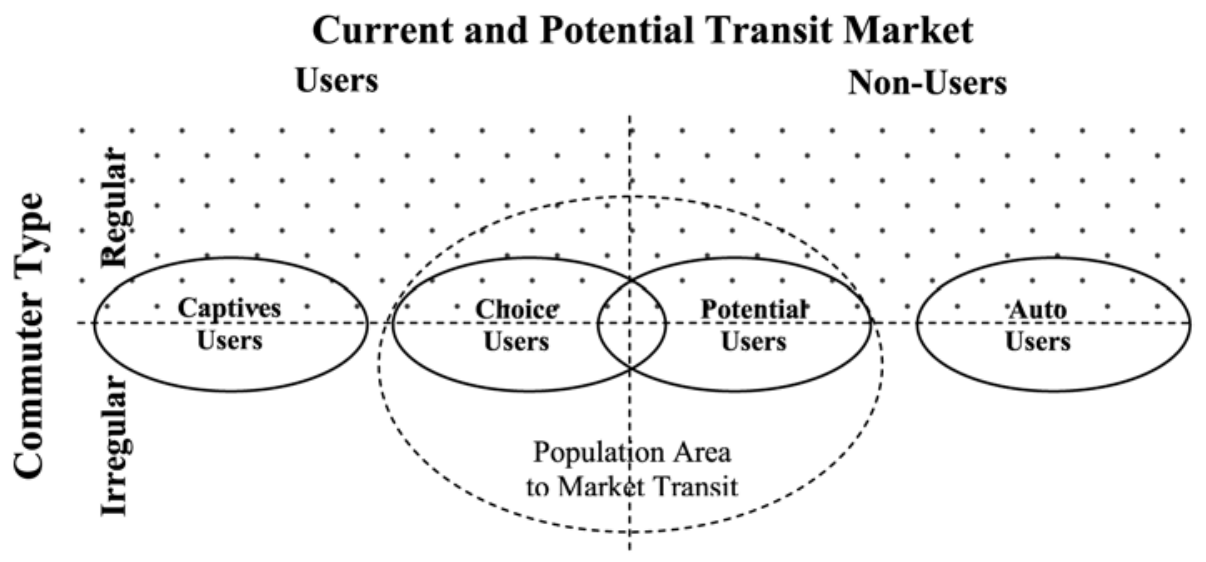

Figure 3. Transit Market Segmentation

Irregular commuters, whom we consider choice and/or potential riders, are concerned with the driver's attitude and travel time. Since regular commuters, whom we consider potential and/or choice riders, have regular commuting habits, they have different concerns. Their concerns stem from safety and comfort of the service provided, reliability of the transit service, the type of service, the amenities 
available nearby transit stations (including park and ride facilities), and some special requests in terms of service frequency and its type. Transit agencies strategically aiming to increase ridership should focus energies on the "population area to market transit services." Transit agencies considered to be more effective attract choice riders from this zone.

Relative to other U.S. transit agencies, this analysis suggests Metro Transit's riders share of the population represented by this zone is limited. Comparing the percentages of captive and non-captives in the Twin Cities region to other metropolitan areas in the United States (where choice riders compose around 70-80 percent of the entire ridership), Metro Transit could serve to attract more choice riders (regular and irregular) by adding improvements in the system. Such improvements are wide ranging. They can include the type of service provide and/or the characteristics of the region they are serving. Increasing the share of choice riders in the "area to market transit services" can be achieved through both improvements in service coverage and reliability.

\section{Conclusion}

The overall objective of this research was to employ a market segmentation approach that would parsimoniously uncover population groups that share similar habits and preferences toward travel generally and transit specifically. Rather than basing any classification strictly on patterns of use, the approach employed here classified riders and non-riders and examines their perspectives towards transit service. To do so, we analyzed two surveys that were administered by Metro Transit, a user and a non-user survey.

In addition to mode captivity, we considered the regularity of commuting habits to better understand the transit market. This is a slightly different strategy than previously used in typical travel analysis. Our statistical analysis yielded users of the system who were classified into four categories: captive riders with regular commuting habits, captive riders with irregular commuting habits, choice riders with regular commuting habits, and choice riders with irregular commuting habits.

Similarly, we classified non-users in four categories: auto captives with regular commuting habits, auto captives with irregular commuting habits, potential riders with regular commuting habits, and potential riders with irregular commuting habits. The data analysis resulted in a number of factors explaining the preferences and attitudes of users and non-users. 
Travel market segmentation is a unique way to understand the transit market, and the eight types of populations who comprise the current and potential transit market yield a different perspective on an age-old phenomenon. Using available survey data, we quantified the size and preferences of different populations. Understanding their attitudes and preferences is an important aspect of retaining current riders and to attract new ones. Providing quality service that addresses the needs of regular captive riders is important since they use the system daily. Auto captives rely on their car as a primary transportation mode, likely because transit service is not possible from their origin to destination. Understanding the preferences of the "area to market transit services" will likely prove most fruitful.

Recent technological advancements provide an opportunity to address several of the attitudes and preferences identified herein. For example, installing cameras inside buses will increase security and possibly reduce vandalism. Automating stop announcements could help riders with disabilities or people unfamiliar with the route. Encouraging the use of swipe cards could decrease travel time by reducing delay during passenger boarding. A next arrival system that displays the time until the arrival of the bus at stops is quickly becoming a common way to improve customer satisfaction. Displaying next arrival time at a stop might help users to choose different routes if the waiting time is too long. Off-line analysis of the existing system in terms of reliability can lead to major improvements in service performance and, accordingly, rider satisfaction, which might lead to an increase in ridership. Such monitoring and analysis of the current service can be used as a decision support system to inform modifications in the existing system that may better address reliability issues.

This analysis suggests that the percentage of choice transit riders in the Twin Cities is low relative to other U.S. transit agencies. However, there is ample opportunity for Metro Transit to increase the number of choice riders using their system through attracting potential riders who represent the majority of the non-user population (around 53 percent). This research has shown that choice users exhibit certain attitudes, some negative, towards transit and preferences for travel, often auto-oriented. This research discovered trends between the two groups that, when considered, could attract potential riders and influence choice riders to become more regular commuters. It has also improved upon previous research by parsimoniously segmenting the transit market differently than previous studies, which tend to only concentrate on captive users. 


\section{Endnote}

' The data were collected by an independent survey consulting firm, Periscope.

\section{References}

American Public Transportation Association. 2006. APTA: Glossary 2003 [cited November, 15 2006]. Available from http://www.apta.com/services/safety/ glossary.cfm\#c.

Chicago Transit Authority. 2005. CTA 2002 budget continues commitment to customers and service. Chicago Transit Authority 2001 [cited November, 1 2005]. Available from http://www.transitchicago.com/news/archpress.wu?action=d isplayarticledetail\&articleid $=102832$.

Domencich, T. A., G. Kraft, and J. Valette. 1968. Estimation of urban passenger travel behavior: An economic demand model. Highway Research Record 238:64-78.

Elmore-Yalch, R. 1998. A handbook: using market segmentation to increase transit ridership. In Transit Cooperative Research Program. Washington DC: Transportation Research Board.

Evans, J. 2004. Traveler response to transportation system changes. In TCRP. Washington DC: Transportation Research Board.

Goodwin, P. B. 1992. A review of new demand elasticities with special reference to short and long run effects of price changes. Journal of Transport Economics and Policy 26 (2):155-163.

Hsiao, S., J. Lu, J. Sterling, and M. Weatherford. 1997. Use of geographic information system for analysis of transit pedestrian access. Transportation Research Record 1604:50-59.

Jin, X., E. Beimborn, and M. Greenwald. 2005. Impacts of accessibility, connectivity and mode captivity on transit choice. Milwaukee, WI: Center for Urban Transportation Studies, University of Wisconsin-Milwaukee.

Kemp, M A. 1973. Some evidence of transit demand elasticities. Transportation 2 (1):25-51.

Kittelson \& Associates. 2003. Transit capacity and quality of service manual. Washington DC: U.S. Department of Transportation. 
Kraft, G., and T. A. Domencich. 1972. Free transit. In Readings in Urban Economics, edited by M. Edel and J. Rothenberg. New York: Macmillian Company.

LaBelle, S., and D. Stuart. 1996. Diverting automobile users to transit: Early lessons from the Chicago Transit Authority's Orange line. Transportation Research Record (1503):79-87.

Lago, A. M., and P. D. Mayworm. 1981. Transit service elasticities. Journal of Transport Economics and Policy 15 (2):99-119.

Lago, A. M., P. D. Mayworm, and M. McEnroe. 1981. Ridership response to changes in transit services. Transportation Research Record 818:13-19.

Levinson, H. 1985. Forecasting future transit route ridership. Transportation Research Record 1036:19-28.

Maruyama, G. 1998. Basics of structural equation modeling. Thousand Lakes, California: SAGE Publications.

Mohring, H., J. Schroeter, and P. Wiboonchutikula. 1987. The value of waiting time, travel time, and a seat on a bus. Rand Journal of Economics 18 (1):40-56.

Murray, A. 2001. Strategic analysis of public transport coverage. Socio-Economic Planning Sciences 35:175-188.

O'Sullivan, A. 2000. Urban Economics. 4th ed. New York: McGraw-Hill Companies, Inc.

Oum, T. H., W. G. Waters II, and J. Yong. 1992. Concepts of price elasticities of transport demand and recent empirical estimates: An interpretative survey. Journal of Transport Economics and Policy 26 (2):139-154.

Outwater, M. , S. Castleberry, Y. Shiftan, M. Ben-Akiva, Y. Zhou, and A. Kuppam. 2003. Use of structural equation modeling for an attitudinal market segmentation approach to mode choice and ridership forecasting. Paper read at 10th International Conference on Travel Behaviour Research, at Switzerland.

Polzin, S. E., R. M. Pendyala, and S. Navari. 2002. Development of time-of-day-based transit accessibility analysis tool. Transportation Research Record 1799:35-41.

Polzin, Steve, Xuehao Chu, and Joel Rey. 2000. Density and captivity in public transit success observations from 1995 nationwide personal transortation study. Transportation Research Record (1735):10-18. 
Pushkarev, B. S., and J. M. Zupan. 1977. Public transportation and land use policy. Bloomington, IN: Indiana University Press.

Rodriguez, D., and A. Ardila. 2002. An empirical exploration of bus travel time and dwell times in highly competitive exclusive busway. Journal of Public Transportation 5 (1):39-60.

Siddall, A., M. Pitstick, and J. Allen. 2006. Transit products, services, and environments in a complex system: User-centered design research in Chicago. Paper read at Transportation Research Board 85th Annual meeting, at Washington DC.

Syed, S., and A. Khan. 2000. Factor analysis for the study of determination of public transit ridership. Journal of Public Transportation 3 (3):1-17.

\section{Acknowledgements}

This research was funded through the ITS institute at the University of Minnesota. The authors thank Ryan Wilson and Michael lacono University of Minnesota for their feedback on early versions of this research.

\section{About the Authors}

KeVIN J. KRIZEK (kjkrizek@gmail.com) is an Associate Professor of Planning and Design at the University of Colorado where he directs the Active Communities/ Transportation Research Group. His research interests include land use-transportation policies and programs that influence household residential location decisions and travel behavior. He has published in the areas of transportation demand management, travel behavior, neighborhood accessibility, and sustainable development. He earned a Ph.D. in Urban Design and Planning and M.S.C.E. from the University of Washington in Seattle. His master's degree in planning is from the University of North Carolina at Chapel Hill and his undergraduate degree is from Northwestern University.

Ahmed EL-Geneidy (geneidy@umn.edu) is a Post-Doctoral research fellow at the Department of Civil Engineering, University of Minnesota and Humphrey Institute of Public Affairs. El-Geneidy's research interests include transit operations, advanced traffic management systems, and accessibility/mobility measures in urban transportation planning. He earned B.S. and M.S. degrees from the Department of 
Journal of Public Transportation, Vol. 10, No. 3, 2007

Architectural Engineering at the University of Alexandria, Egypt, and continued his academic work at Portland State University, where he received a Graduate GIS Certificate and earned a Ph.D. in Urban Studies. 